\title{
Análise dos discursos: uma forma de combate ao racismo sob perspectivas filosófica e discursiva
}

\author{
Discourse analysis: a way of combating racism \\ on philosophical and discursive perspectives
}

\author{
Célia Zeri de Oliveira \\ Professora na área de ensino-aprendizagem \\ de línguas da UFPA e \\ Isabella Vivianny Santana Heinen \\ Professora substituta de filosofia da UEPA
}

Resumo: Neste artigo fazemos uma reflexão filosófico-discursiva acerca das relações étnico-raciais no contexto social atual em que a sociedade brasileira, uma vez constituída por meio da miscigenação de povos e suas respectivas culturas, raramente tem atribuído o protagonismo a todos os componentes que são parte da história da nação, pois tem havido dois grupos sociais sistematicamente excluídos e apagados do processo de construção da cultura brasileira: os negros e os indígenas. A linguagem, nesse âmbito, serve para a estruturação das relações sociais e, em simultâneo, também é usada para a manutenção do status quo como estruturas das hegemonias de poder e dominação de uns sobre outros, tal qual um mecanismo naturalizado e aceito pelos integrantes desse sistema, sejam eles os dominadores ou dominados. Metodologicamente realizamos a análise discursiva com base em interpretações dos gêneros discursivos/textuais utilizados 
nos meios de informação e comunicação em nossa sociedade, especificamente, selecionando em meio a textos jornalísticos publicados via internet e com assinatura de autores que defendem um ou outro ponto de vista discursivo em relação às relações étnico-raciais presentes em nossa sociedade. Assim, discutimos os princípios éticos pelo viés filosófico como base para a construção coletiva de princípios, principalmente os que se inserem nas relações étnico-raciais.

Palavras-chave: Discurso; Filosofia; Étnico-Raciais; Reflexão.

Abstract: In this article we do a philosophical-discursive reflection about ethnic-racial relations in the current social context in which the Brazilian society, once constituted through the miscegenation of peoples and their respective cultures, has rarely assigned the protagonism to all the components that are part of the history of the nation, considering that there have been two social groups systematically excluded and erased from the process of construction of Brazilian culture: Blacks and Indians. Language, in this context, serves to structure social relations and, at the same time, is also used for the maintenance of the status quo as structures of hegemonic power and domination over one another, just as a mechanism naturalized and accepted by the members of this system, as dominators or dominated. Methodologically, we choose the discursive analysis based on interpretations of the discursive / textual genres used in the media and communication in our society, specifically, selecting among of journalistic texts published via the internet, with the signature of authors who defend one or another discursive point of view in relation to the ethnic-racial relationships present in our society. Thus, we discuss ethical principles by philosophical bias as the basis for the collective construction of principles, especially those that are embedded in ethnic-racial relations.

Keywords: Discourse; Philosophy; Ethnic-Racial; Reflection.

\section{Contextualização dos estudos acerca das relações étnico-raciais na educação básica}

s reivindicações de organizações defensoras dos direitos
dos negros para a inclusão, respeito e valorização de sua 
cultura nos currículos escolares têm surtido alguns efeitos, a exemplo as ações governamentais alicerçadas na desconstrução do mito da democracia racial, conquistada pela aprovação da Lei 10.639/2003 que modifica as instruções da LDB 9.394/1996, assegurando a obrigatoriedade da inserção da história e cultura afro-brasileira e africana no currículo escolar da educação básica, tanto nos estabelecimentos de ensino públicos como nos privados. Em seguida, expandida pela Lei $11.645 / 2008$, que admite os princípios da Lei antecedente citada acima, tornando ainda obrigatórios nos currículos escolares do ensino fundamental e médio a história das culturas indígenas, salientando suas lutas e contribuições para construção territorial e populacional do Brasil.

Embora essas transformações demonstrem um amplo avanço para a inserção da temática étnico-racial nos currículos escolares, ainda são insuficientes no que se refere à capacitação dos profissionais que precisam operar com os conteúdos recomendados pela legislação. Em meio às dificuldades encontradas no ambiente escolar e com os desafios apresentados pelas leis $10.639 / 2003$ e $11.645 / 2008$, os educadores se deparam com as adversidades de promover um ensino adequado dessas culturas sem disporem de formação equivalente.

Coelho (2012) discute a formação de professores e as relações raciais de acordo com a Lei 10.639/2003, considerando dois aspectos: o primeiro é a inclusão de conteúdos novos que tratem das relações étnico-raciais e ensino de História e cultura afro-brasileira e africana; o segundo refere-se ao cumprimento da mesma lei, tendo em vista a necessidade de divulgação e orientação aos profissionais da educação, tanto no âmbito da falta de formação dos docentes quanto nos mecanismos de sua aplicação. Desse modo, a referida Lei é destacada pela autora como oportunidade de problematizar e refletir sobre circunstâncias ditas normais, como vinculações entre negro e pobreza e, negro e violência, possibilitando uma perspectiva diferente de interpretação, expandindo o tema da inclusão e combatendo a reprodução do preconceito e da discriminação. 
É necessário, nesse contexto, compreender como as relações sociais fundamentadas em bases preconceituosas e racistas foram se construindo ao longo do tempo. De acordo com Chartier (1991) as considerações sobre raça, etnia e cor remontam a concepção de representação, pois tratam-se de produções sociais fundamentadas nas relações constituídas entre os vários atores inseridos em um âmbito histórico-social conhecido em que os conceitos de supremacia e de superioridade de alguns em relação aos outros foram crescendo sutilmente por meio da aceitação social das diferenças como base para a consolidação de uma sociedade injusta e desigualitária.

Para trabalhar essas representações nas escolas do Brasil é importante reportar pesquisas tais quais Coelho (2010) acerca das representações dos atores da escola no que diz respeito às questões étnico-raciais. Nesse sentido, baseada nas formulações de Chartier (op. Cit.) a autora compreende que para o debate dessa problemática no espaço escolar as representações se estabelecem como atributos dos agrupamentos criadores das mesmas e são desenvolvidos historicamente, resultando em indicadores de constatação da maneira pela qual os agentes sociais manifestam suas interpretações de si mesmos e daquilo que está a sua volta, evidenciando-se que tais construções estão continuamente em processo de elaboração, enquanto integrantes das lutas sociais quando articuladas às técnicas de dominação e classificação de grupos adversários ou reconhecidos como inferiores.

Coelho (2010) apresenta a criação e a inserção, no cotidiano do Brasil, da intensa representação de liberdade e complacência racial, validando práticas amistosas entre as diferentes etnias concernentes à sociedade brasileira e reduzindo as oportunidades de combate às ocorrências vivenciadas pela população negra. Dessa maneira, o racismo ocorre, justamente com os mecanismos de dissimulação adotados e consolidados. Em vista disso, Coelho e Silva (2013) reforçam a relevância de além de denunciar, problematizar as temáticas étnico-raciais nos diversos aspectos de escolarização, pois ainda observa-se uma grande relutância em se levantar essas questões na escola, pontos essenciais que buscamos problematizar ao longo deste artigo. 


\section{Os pressupostos filosóficos para refletir as questões dos valores humanos}

Pierre Vernant, na obra Mito e pensamento entre os gregos (1990) situa o pensamento racional como tendo seu início no momento em que o homem é legitimado como sujeito pensante, como sujeito capaz de compreender os fenômenos da natureza a partir de explicações baseadas em argumentos racionais. A polis representa o início da vida social e intelectual, refletindo no engendramento das instituições, tendo como fator preponderante o uso da palavra enquanto mecanismo de dominação. A arte da oratória representava a expressão dos discursos e argumentações, por meio de proposições passíveis de serem contra-argumentadas, exprimindo em tal medida uma conexão significativa entre a política instaurada na polis e o logos.

Instaura-se por meio das implicações racionais instituídas na polis o início da experiência civilizatória, em que a ética, ao longo da história, se constituiu enquanto plano intelectual de práticas reflexivas, fundamentando seu campo de apreciação por meio de determinações que visem o bem comum. Dessa maneira, a filosofia grega, ao tratar dos princípios éticos, baseia-se no respeito universal, no conhecimento do outro em sua individualidade, na liberdade de expressão, da reivindicação e mudança das Leis impostas, na solidariedade indistinta e no exercício de sua identidade autônoma. A política visa a garantia de uma cidadania voltada aos direitos igualitários do cidadão, da supervisão dos direitos e deveres do indivíduo enquanto membros de uma sociedade complexa e de prática da democracia.

No entanto, o debate filosófico contemporâneo começou a verificar os distintos âmbitos da vida social, especialmente no que tange ao uso da razão como medida para todas as coisas, pois a racionalização servia como instrumento de controle dos indivíduos, por isso questionava-se as mais variadas maneiras de oprimir e engessar o homem em sua vida cotidiana. Ao abandonar a ideia de totalidade, a filosofia contemporânea trabalha com um mecanismo fragmentário de denúncia, já que evidencia questões diversas e singulares do dia-a-dia, portanto, não mais apresentando uma noção de conjunto, e sim 
uma perspectiva de diversidade, singularidade, valorizando as pluralidades culturais com o objetivo de respeitar as diferenças.

Nesse âmbito, Nietzsche (1992b) propõe à filosofia, a partir de moldes antagônicos aos dos estabelecidos desde o racionalismo socrático, ou seja, o filósofo em questão tratou de questões filosóficas com a mesma seriedade que geralmente a filosofia tradicional trata, porém utilizando da via poética, não se limitando ao modo de conceituação próprio da filosofia. Sem obedecer à racionalidade pretendida desde Sócrates ${ }^{1}$, Nietzsche ressalta que "aquele idílico pastor do homem moderno é apenas uma réplica da suma das ilusões culturais que para este último vale como natureza; o grego dionisíaco, ele, quer a verdade e a natureza em sua máxima força - ele vê a si mesmo encantado em sátiro" (Nietzsche, 1992b, §8). Em tal medida, Nietzsche afasta-se dos princípios metafísicos da cultura ocidental e aproxima-se do deus Dioniso, contrapondo-se à ideia de conceito engendrado pela tradição socrática.

Para Nietzsche (op. Cit.), ocupar-se moralmente de questões relativas ao homem e ao seu conhecimento, pressupõe questionar a proveniência de tais valorações. Esse direcionamento da crítica nietzschiana à modernidade, pertinente à ação moral realizada sobre o homem, apoia-se na tentativa de justificar a proveniência de determinadas estruturas modernas a partir de bases valorativas. Por isso, a modernidade estabelecida pela relação entre os homens e pelo desejo instaurado através da razão de se alcançar a verdade, apresenta em sua configuração os reflexos da tentativa de dominação como mecanismo de uma regulação da vida em sociedade.

Nesse âmbito, Machado salienta que Nietzsche "negará a existência de um desejo natural de verdade através de uma concepção do intelecto como tendo um efeito específico de dissimulação" (Machado, 1999, p. 37). Ou seja, Nietzsche expressa que o homem, na modernidade, tão arrogante de sua

$1 \quad$ Compreende-se de tal modo, que o princípio racional exaltado tanto por Sócrates, quanto por Platão, pauta-se na intenção de moralização, do estabelecimento de um modelo geral de representação do homem, em que a razão é posta como forma de comedimento dos instintos, por estes remeterem ao rebaixamento do humano. 
civilidade, de sua convivência em sociedade com os outros homens, coloca a verdade como baliza para o funcionamento da comunidade, desfavorecendo as suas intuições e sensações, e, por outro lado, favorecendo a negligência do homem moral, que tem por desígnio a verdade.

Seguindo essa reflexão, Foucault (1995), a partir da concepção nietzschiana, destaca a ideia de microfísica do poder, entendendo que o poder encontra-se em todos os lugares, não por abarcar tudo, mas por ser proveniente de todos os lugares. Para esse filósofo, o homem se depara mais com os detentores dos micropoderes ou poderes periféricos do que com os dos macropoderes. Seu intento, com essa análise, foi evidenciar as estruturas mascaradas, implícitas de poder, demonstrando a relação intrínseca entre saber e poder, haja vista que, para ele, a sociedade cria determinados discursos que se apresentam como verdades e, por isso, alcançam poderes específicos.

Desse modo, adentrar nesse solo moral requer a disposição para percorrer as camadas mais profundas que se alicerçam na ética, provenientes desta, o impulso causador das acepções de valor engendradas por uma lógica que não permite alteração. Nietzsche (2009a) corrobora sua interpretação, ressaltando os desdobramentos que a temática valorativa opera acerca da moral na obra "A genealogia da moral" (2009a), em que discorre a respeito da proveniência da moral moderna, propondo-se a analisar as alterações a que foi exposta no decorrer das épocas, argumentando que ela não é derivada de um ponto de partida originário e determinante.

Nessa perspectiva, o filósofo citado conta a história da construção de uma moral, que é a expressão de um modo valorativo de dominação e opressão, em que todos os sistemas morais, em última análise, derivam dessas características, tendo como principal interesse a crítica e a ruptura com o sistema platônico ${ }^{2}$, apontando que a troca de um sistema valorativo será sempre a troca da forma de opressão.

$2 \quad$ A teoria das ideias de Platão é a base para sua lógica e metafísica, assim como para a teoria do conhecimento e sua concepção de moral. De um lado, tem-se a eidética platônica, o mundo inteligível, em que a ideia é a forma pura, a essência, esta representa o modelo originário - o arquétipo - das 
O problema da opressão ocidental, afirma Nietzsche (op. Cit.), é que quando se perde de vista a violência metafísica, e, também a moral judaico cristã, porque se considera esses valores como uma fundamentação ontológica divina, por conseguinte, não podem ser criticados e nem ter a pretensão de se afastar da moral já estabelecida. Para o filósofo alemão, a origem da cultura genealogicamente empreendida pode evidenciar o processo de dominação a ela iminente, o que pode servir de meio a uma crítica da modernidade e seus ideais.

A modernidade política, para Nietzsche (op. Cit.), ao contrário de proporcionar uma perspectiva positiva no que tange a economia e seus efeitos, instaura um processo comparado a uma escravização do homem e de sua força produtiva. "O prognóstico nietzschiano pode ser assustador, haverá uma progressiva escravização das massas, um domínio cada vez mais despótico sobre a população, até chegar ao extermínio de inúmeros grupos" (Barrenechea, 2003, p. 43). Uma tentativa de eliminar as singularidades de cada um, em prol de um aprimoramento do todo, cuja estruturação minimiza as forças criativas e provoca danos ao indivíduo, o que, por conseguinte, afeta de maneira geral a todos da sociedade.

A fixação pela razão que move o ideário de progresso tecnológico e científico alavanca as estruturas industriais e liberais através de políticas que estimulam a ideia de igualdade, de modo que, segundo a interpretação nietzschiana, nenhum desses animais de rebanho, pesados e de consciência inquieta (que pretendem dissimular os interesses do egoísmo sob os do bem-estar geral) quer entender ou pressentir, que o bem-estar geral não é um ideal, uma meta, um conceito que se possa formular claramente, mas sobretudo um meio de abrir uma passagem que permita apenas um vau e nenhum outro, que ao pretender uma única moral para todos tende precisamencoisas que compõem o mundo material, e que na ontologia desse modelo, possuem dinamicidade e vitalidade. Prevalece aqui a ideia do Bem, do Belo, da Alma como realidades puras, transcendentais, universais e eternas. Do outro lado está o mundo sensível, material, puramente aparente, em que este é representado pelo homem, a natureza, o universo, as coisas. Em base a esse jogo de contrários, a essa antinomia, Platão acena que a segunda realidade nada mais é do que a predicação da primeira. 
te a golpear os homens superiores, que existe uma diferença de grau entre os homens e consequentemente entre as morais (Nietzsche, 1992a, §228).

Essa tendência a uma moral de rebanho é proveniente de um emprego valorativo autoritário e dominador, com a pretensão de eleger o valor de todos os valores, e assim, concentrar o homem em uma única via de acepção, em um único modo moral aceitável de legitimação. Considerando isso, pode-se destacar que Nietzsche, a respeito da crítica mobilizada à modernidade, reconhece o mundo europeu como uma representação da unanimidade de uma moral, estabelecida pela diligência de designar o que seja certo e o que seja errado, o que entendemos como uma conduta inadequada aos convívios entre diversidades e as relações étnico-raciais.

\section{A valorização da cultura africana através da filoso- fia africana}

A partir do século VII a.C., na Grécia antiga, surgiram renomados filósofos e a filosofia demarcou vários períodos gregos, constituídos pelos pré-socráticos, socráticos e helenísticos. Sendo esta a área do saber preocupada em conhecer de maneira clara e racional, a natureza, o homem e o universo e as transformações ocorridas neles, continua a exercer estimada influência na edificação da sociedade que a estabelece.

Todavia, observa-se que, segundo autores como Enrique Dussel e Renato Nogueira, a filosofia não nasceu na Grécia, tal qual indicam livros em distintos momentos e correntes historiográficas. Para esses autores a filosofia surgiu na África, bem como inúmeros outros conhecimentos e as estratégias colonialistas que lhes foram furtados o direito de berço. Nogueira (2014) destaca a convenção de que a Filosofia nasceu na Grécia, evidenciandose um racismo ou superioridade epistemológica que impossibilita estruturalmente a criação filosófica não ocidental, observando, principalmente, a presença da filosofia africana. Discute-se, a partir da exigência da Lei 10.639/03 a transformação da concepção do ensino de Filosofia, pretendendo-se criar meios para uma 
forma descolonizada de pensar, percebendo o valor da Filosofia Africana e a pluriversalidade da Filosofia.

De acordo com Asant (2014), estudioso Afro-americano, historiador e filósofo, incontáveis gregos conheceram e aprenderam filosofia na África, principalmente no Egito e na Etiópia, apesar de esses lugares serem entendidos como propulsores da civilização anterior aos pré-socráticos, a saber: Thales, Pitágoras, Homero e Heródoto são identificados por terem vivido e se educado no continente africano, possibilitando a compreensão de que eles receberam fortes influências dos povos, das culturas e do ensino, fazendo repercutir em suas concepções racionais as análises do universo. Entretanto, na adoção do modelo mundial em vez do eurocêntrico, destaca-se uma separação do sistema -mundo em centro e periferia, cuja Europa representa o centro e a África a representação da periferia, delimitando a modernidade por meio de um modelo mundial, um acontecimento específico do sistema expressado pela visão de centro e periferia.

Para Dussel (1992), filósofo argentino radicado no México, um dos maiores representantes da Filosofia da Libertação e do pensamento latino-americano em geral, a Europa tornou-se o centro do sistema-mundo devido ao desdobramento, colonização, conquista e subsunção da América, conferindo à Europa um benefício importante sobre o mundo otomano-mulçumano, à China ou à Índia. "Detentora da administração do centro do sistema-mundo, nada tem que aprender de outros mundos, outras culturas. Tem um princípio em si mesma e é sua plena realização" (Dussel, 1992, p. 26). Ela é a norteadora da consciência reflexiva da modernidade e da história. O principal marco histórico responsável por suas vantagens no que concerne a sua relação com as outras culturas, o poder econômico e político inigualáveis na história mundial, deu-se pela incorporação Ameríndia e, não pelo Renascimento no século XIV ou pela revolução científica no século XVII.

Corroborando a discussão com Nietzsche, o filósofo Dussel procura problematizar o que a filosofia havia produzido até então, especialmente no que diz respeito à questão moral, pois conjecturaria ser um grande equívoco, de tal modo, que a 
busca da verdade pelos filósofos ocidentais designaria o alcance da sabedoria, acenando que a verdade talvez não exista, e a sabedoria, por sua vez, poderia encontrar-se na mentira.

Desse modo, o sistema moderno e capitalista europeu foi tomado como o único sistema-mundo existente, porém, a ética da Libertação de Dussel salienta uma interpretação do sistema-mundo contrária à submissão ao seu centro, por encontrar-se nas áreas periféricas do sistema, procura estabelecer relações com o centro em função de outra conjuntura:

Porque a experiência inicial da Filosofia da Libertação consiste em descobrir o "fato" opressivo da dominação, em que sujeitos se constituem "senhores" de outros sujeitos, no plano mundial (desde o início da expansão europeia em 1492; fato constitutivo que deu origem à "Modernidade"), centro-periferia; no plano nacional (elites-massas, burguesia nacional-classe operária e povo); no plano erótico (homem-mulher); no plano pedagógico (cultura imperial, elitista, versus cultura periférica, popular, etc.); no plano religioso (o fetichismo em todos os níveis), etc. (Dussel, 1995, p. 18).

Preocupa-se em discorrer acerca das questões sócio-histórica, política e econômica da periferia, apresentando de forma crítica as formulações contraditórias da soberania do centro, observando outras perspectivas teóricas e especialmente práticas capazes de equilibrar a heterogeneidade econômica e social entre a periferia e o centro, derivado do procedimento histórico iniciado em 1492 com o oportuno sistema-mundo, progredindo do capitalismo mercantil para o industrial e, hodiernamente para o globalizado.

Com a ética da libertação, Dussel fala da "transformação como possibilidade da reprodução da vida da vítima e como desenvolvimento factível da vida humana em geral" (Dussel, 2000, p. 564), sugerindo uma ética dos vitimizados do sistema-mundo, processo de libertação a ser alcançado cotidianamente, posto que esse filósofo quer considerar a sua ética como a do cotidiano, da vida, construída em fundamentações anti-hegemônicas, nesse aspecto, afastando-se dos reducionismos etnocêntricos e falso-universalista, oportunizando o princípio de alteridade excluída das vítimas: 
Aceitar o argumento do outro supõe aceitar ao outro como igual, e esta aceitação do outro como igual é uma posição ética, é o reconhecimento ético ao outro como igual, quer dizer, aceitar o argumento não é somente uma questão de verdade é, também, uma aceitação da pessoa do outro (Dussel, 2001c, p. 8).

O preceito material universal de verdade aplicada assenta como mecanismo de orientação para definir as intermediações necessárias à construção, reconstrução e desdobramento da vida em sociedade, "vale o que tem relação com a vida, não vale o que não tem relação com a vida. Vale mais o que mais tem relação com a vida" (Dussel, 2001b, p. 9). Admitindose a vida humana como condição de realidade do sujeito ético, seguindo este preceito, todo sentido demandado pela vida humana tal como se alimentar para não morrer. De modo que, ao se falar da razão prático-material, encontra-se nela a razão que baseia a ligação de um juízo material representado para uma enunciação material ético-normativo.

Por sua vez, a ética, para Nietzsche, contra a moral dogmática é a ética do "tornar-se o que se é", ou seja, cada um individualmente busca aquilo que é mais apropriado para si, diferentemente de toda concepção ética universalista, que o antecedeu. O que se busca é o processo e, não uma finalidade, um objetivo a ser alcançado.

Em Dussel (op. Cit.) a filosofia da libertação refere-se à dinâmica promovida pelos filósofos da América latina, como consequência da efetividade da globalização, da supressão. Exerce crítica à tensão de um sistema-mundo, ao qual retrata temáticas libertadoras do homem periférico, lugares convertidos em vítimas do grande aproveitamento econômico.

A Europa autoproclamou-se como centro enquanto a África foi rebaixada à periferia, incutida na ideia de subordinação econômica. Para Dussel, a filosofia da libertação "é mudar o rumo de uma intenção, o conteúdo de uma norma; modificar uma ação ou instituições possíveis, e até um sistema de eticidade completo, em vista dos critérios e princípios éticos enunciados, no próprio processo estratégico e tático" (Dussel, 2000, p. 539). Manifestando-se contra as ferramentas de do- 
minação usadas para expressar a dependência e inferioridade da África, fazendo ressaltar seus valores e autonomia reflexiva.

Dessa maneira, a filosofia da libertação de Dussel objetiva uma justiça que haja em conformidade com o outro, em que a África exerça seu papel visando transpor-se à dominação europeia, contrariando o lugar de periferia associado a ela, para que o sistema-mundo seja suprimido e a política de alteridade potencialize-se.

\section{O uso dos discursos como forma de hegemonia e manu- tenção das estruturas sociais tais quais se apresentam}

Em se tratando dos estudos relativos à língua, de acordo com Possenti (2012 p. 242) postulamos que a "língua não é transparente", isto é, ao utilizá-la o indivíduo sempre fará uma tomada de posição, que poderá ser positiva, negativa, ou afirmativa, considerando-se que, qual seja a língua em questão há sempre pré-estabelecido um funcionamento, ou, uma ordem própria. Entretanto, a língua é simbólica, isto é, exerce a função de construção simbólica do mundo por meio da representação, tanto no que se refere ao relacionamento do ser humano com a natureza quanto com os seus semelhantes. Assim, a interação social por meio da língua é caracterizada, fundamentalmente, por meio da argumentatividade. Segundo Koch (2008, p. 17) "como ser dotado de razão e vontade, o homem, constantemente avalia, julga, critica, e assim, forma juízos de valores".

As ações sociais são, assim, realizadas por intermédio do discurso, ações verbais dotadas de intencionalidade que têm por objetivo tentar influenciar no comportamento do outro ou ainda fazer com que o seu interlocutor compartilhe com o outro suas opiniões, valores, formas de pensar e de construir conhecimentos. Consequentemente, a neutralidade na língua deve ser tratada como um mito, uma vez que a todo discurso subjaz uma ideologia em sua acepção mais ampla, configurando-se, assim, os atos ilocucionários e os atos perlocucionários, em que os primeiros encerram a forma com que os enunciados são produzidos e os últimos dizem respeito aos efeitos preten- 
didos pelo uso da linguagem, entre os quais estabelecem-se as metas de convencer e de persuadir (Koch, 2008).

Quanto aos objetivos da argumentação é de consenso que, de algum modo, vise provocar a adesão dos interlocutores aos sentidos que se pretende promulgar ao efetivar um enunciado, caracterizando-se como um ato persuasivo no qual,

o ato de convencer se dirige unicamente à razão, através de um raciocínio estritamente lógico e por meio de provas objetivas, sendo, assim, capaz de atingir um "auditório universal", possuindo caráter puramente demonstrativo e atemporal [...]. O ato de persuadir, por sua vez, procura atingir a vontade, o sentimento do interlocutor por meio de argumentos plausíveis ou verossímeis e tem caráter ideológico, subjetivo, temporal, dirigindo-se, pois, a um "auditório particular" (Koch, 2008, p. 18).

Em decorrência disso, postula-se que a argumentatividade está inscrita no nível fundamental da língua. Entretanto, a língua é uma das formas de linguagem, sendo esta um sistema de significações que medeia a existência humana. As relações que mantemos com o outro acontecem por meio da linguagem, e essas relações sociais influenciam os padrões daquilo que é dito, como é dito e quando é dito. Desse modo, de acordo com Bernstein (1990) a seleção e a organização dos significados são posicionados dentro das divisões sociais, sendo assim, o texto, ou seja, a forma materializada de linguagem, a forma visível e palpável da relação social, podendo-se observar as práticas sociais por intermédio da realização dos textos. De acordo com Cloran (2000),

a relação entre três elementos centrais - os significados considerados relevantes, as formas linguísticas que realizam esses significados e os contextos que os evocam - variam conforme a posição do sujeito, usuário da linguagem, quanto a seu maior ou menor grau de poder na sociedade (Cloran, 2000, p. 155).

Há que se destacar, assim, a importância do contexto para a realização de qualquer fato social, podendo-se tratar acerca do contexto da situação e do contexto da cultura, sendo que o primeiro é um sistema de relevâncias motivadoras para o uso da linguagem, constituindo uma força dinâmica para a criação e interpretação do texto. O contexto da cultura, consequente-

Destaques da autora 
mente, trata-se de um sistema de experiências com significados partilhados, desse modo, o sujeito é constituído pela soma das duas interações e pelos códigos semióticos em funcionamento na comunidade da qual participa. De acordo com Halliday e Hasan (1989) o contexto da situação compreende aquilo que é relevante para a interação e define-se por três variáveis: o campo, qual seja, a natureza da prática social; a relação, quer dizer, a natureza da conexão entre os participantes da situação e o modo, isto é, a natureza e o meio da transmissão da mensagem.

Dentro do contexto essas três variáveis são realizadas por meio de três metafunções da linguagem:

A metafunção ideacional-cuja função é de expressar o conteúdo do texto, tornando possível que o sujeito tire partido da possibilidade atribuída à linguagem de representar as experiências de seu mundo interior e exterior.

A metafunção interpessoal - em que a função de expressar as interações sociais em que o sujeito participa, possibilitando representar as ações sobre os outros dentro de cada domínio social.

A metafunção textual - na qual expressa a estrutura e o formato do texto, o que possibilita que o sujeito estruture as experiências construídas em textos coerentes a partir do sistema linguístico de sua escolha.

Essas metafunções permitem que o sujeito tenha conhecimento e experiência em materialização da linguagem para representar o contexto social como um jogo semiótico no qual cada ator social vivencia significados.

Da mesma forma que se constroem os significados por meio da materialização dos atos sociais por meio da construção dos gêneros textuais, faz-se necessário que se observe e analise esses objetos discursivos dentro do ambiente em que são construídos, sendo necessários métodos de estudos para que essa compreensão seja efetivada. Especificamente, não existe uma análise de discurso como um método, assim como não apenas uma análise social de fatos, mas é possível estudar estratégias de textos escritos ou falados, como por exemplo, o estudo das 
notícias jornalísticas como forma de persuasão ou de convencimento e ideologias, conforme faremos nesse artigo.

Van Dijk (2008), como exemplo de análise e compreensão do discurso, trata de observar os discursos e a reprodução do poder social que estes representam, definindo o poder social em termos de controle, isto é, de controle de um grupo sobre outros grupos e seus membros. Dessa maneira,

tradicionalmente, controle é definido como controle sobre as ações de outros. Se esse controle se dá também no interesse daqueles que exercem tal poder e contra os interesses daqueles que são controlados, podemos falar em abuso de poder. Se as ações envolvidas são ações comunicativas, isto é, o discurso, então podemos, de forma mais específica, tratar do controle sobre o discurso de outros, que é uma das maneiras óbvias de como o discurso e o poder estão relacionados: pessoas não são livres para falar ou escrever quando, onde, para quem, sobre o que elas querem, mas são parcial ou totalmente controladas pelos outros (Van Dijk, 2008, p. 18).

Desse modo, o controle não se aplica apenas ao discurso como prática social, mas também às mentes daqueles que estão sendo controlados, aos seus conhecimentos, opiniões, atitudes e ideologias, assim como as representações pessoais e sociais. Nesse aspecto, Miller (2012) postula que o gênero torna-se mais que uma entidade formal, ele se transforma em algo pragmático e completamente retórico, fazendo um ponto de ligação entre intenção e efeito, configurando-se num aspecto da ação social. O gênero recebe, assim, uma classificação aberta - em vez de fechada - e organizada em torno das ações situadas, em outras palavras, pragmáticas.

Ao analisarmos a linguagem numa perspectiva crítica, inclinamos para uma forte preocupação social desse estudo, uma vez que as questões sociais têm um caráter parcialmente linguístico-discursivo pelo modo no qual revelam questões importantes das estruturas de nossas sociedades. Assim, ao fazerse a análise crítica de textos não se sobressaem somente as características dos textos em si, mas principalmente destacam-se maneiras de representar a realidade, assim como manifestações de identidades e relações de poder na sociedade em questão. 
Seguindo premissas de uma perspectiva teórica para análise de gêneros, de acordo com Fairclough (1989), podemos considerar que,

$1^{\circ}$ a linguagem é uma forma de prática social, havendo sempre a bidirecionalidade entre os textos e a sociedade, assim, as formas discursivas e a sociedade influenciam-se mutuamente.

$2^{\circ}$ a linguagem, em manifestações discursivas, tem poder constitutivo. O discurso, por assim ser, cria, reforça ou desafia as formas de conhecimentos, as crenças, as identidades e as posições sociais.

$3^{\circ}$ os textos são perpassados por relações de poder e a linguagem é utilizada para manter ou para desafiar essas relações.

$4^{\circ}$ as formas de poder se articulam com uma espécie de trabalho ideológico que se realiza em diferentes discursos e com finalidades diversas dentro dos contextos sociais e culturais.

Desse modo, os textos, ao mesmo tempo que criam formas de perceber e representar o mundo, as relações com o outro e as identidades apresentadas nessas interações, são também perpassados por relações de poder e hegemonia em que o poder insere-se na capacidade que os indivíduos ou instituições têm de utilizar os recursos da linguagem para agir socialmente, e a hegemonia, uma espécie de liderança em relação aos domínios econômico, político, cultural e ideologia de uns sobre outros.

\section{O éthos do autor}

Os discursos são materializados por meio dos gêneros textuais, textos que fazem a função de transformar em elementos concretos os objetos da vontade e da intencionalidade dos interlocutores, construindo, desse modo, os argumentos, isto é, as proposições destinadas a se construir uma dada tese. Argumentar, assim, é construir um discurso com a finalidade de persuadir, e como qualquer discurso, o argumento é um enunciado por se inserir num processo de enunciação que põe em jogo três elementos principais: o enunciador, o enunciatário e o discurso (Fiorin, 2017). Destarte, em se tratando de retórica, 
três elementos concorrem simultaneamente para a persuasão: o éthos do orador, o páthos do auditório e o lógos, o discurso. Nesse contexto, o orador e o auditório assumem papéis socialmente determinados com suas construções determinadas pelo próprio discurso.

De acordo com Bakhtin (2009) a língua tem como constituinte a interação verbal e a enunciação, é, senão, o resultado da interação entre dois indivíduos, o locutor e o interlocutor que se estabelecem socialmente, entretanto, na ausência real do interlocutor este poderá ser substituído pelo representante do grupo social ao qual pertence o próprio locutor, uma vez que não há um locutor abstrato. "É a ele que se encaminha a palavra, esta é a função da pessoa desse interlocutor" (Bakhtin, 2009, p. 112). Na maior parte dos casos, é preciso supor um certo horizonte social definido e estabelecido que determina a criação ideológica do grupo social e da época a que pertencemos, um horizonte contemporâneo à nossa literatura, da nossa ciência, da nossa moral, do nosso direito.

Nessa concepção, cada indivíduo possui um auditório social em que se constroem suas deduções interiores, suas motivações e apreciações, e quanto mais aculturado este se torna mais se aproxima do auditório médio da criação ideológica. A palavra, assim, possui dois lados a serem destacados: procede sempre de alguém e sempre se dirige a alguém, tornando- se o território comum do locutor e do interlocutor. Desse modo, o enunciador, ao construir o seu discurso edifica uma imagem de si, a essa imagem denominamos éthos do enunciador. Cabe destacar que é o étho sque leva à persuasão.

De acordo com Aristóteles, apud Fiorin (2017, p. 70),

É o éthos (caráter) que leva à persuasão, quando o discurso é organizado de tal maneira que o orador inspira confiança. Confiamos sem dificuldade e mais prontamente nos homens de bem, em todas as questões, mas confiamos neles de maneira absoluta, nas questões confusas ou que se prestam a equívocos. No entanto, é preciso que essa confiança seja resultado da força do discurso e não de uma prevenção favorável a respeito do orador (I,II, IV, 1356a). 
A inspiração de confiança do éthos do autor está diretamente relacionado ao perfil que o autor constrói ao longo de sua vivência social, ou seja, os estudos que realiza, a formação profissional, as ideologias às quais inscreve seu discurso, os atos praticados, em suma, o seu histórico de indivíduo inserido na sociedade e construído por atitudes pessoais dentro de uma sociedade coletiva.

Fiorin (2017) afirma que há três coisas que inspiram confiança no orador, pois há também três razões que nos levam à convicção, independente das demonstrações que se fazem: são o bom senso, ou seja, a sabedoria prática (phrónesis), a virtude (areté) e a benevolência (eunoia). Assim, o orador pode afastar-se da verdade por todas essas características ou então, por uma ou outra delas. Devido à falta de bom senso poderia não exprimir uma opinião correta, devido a uma espécie de malvadeza poderia não expressar exatamente aquilo que pensa e ainda mesmo sendo prudente e honesto pode optar pela ação não benevolente. Assim, em cada ato social pode-se avaliar se o orador, descrevendo-se seu éthos, inspira confiança, argumenta com honestidade e é solidário com o outro.

\section{A apresentação do gênero discursivo, análises e en- caminhamentos metodológicos}

Os excertos que apresentamos a seguir e suas categorizações foram destacados com o intuito de dar visibilidade às formas as quais os meios de comunicação são utilizados em nossa sociedade como modo recorrente na manutenção de conceitos preconceituosos e atitudes racistas, mesmo que, de certo modo, disfarçados por meio das articulações possíveis de serem realizadas pelo uso da linguagem, ou seja, dos gêneros discursivos que cumprem o papel de refletir e refratar ideologias.

O cidadão comum, ao ouvir o programa de rádio em que tem como comentador o renomado historiador brasileiro, dará crédito ao seu discurso sem qualquer questionamento, uma vez que a intencionalidade presente na matéria apresentada e difundida por meio do programa na Rádio Jovem Pan 
cumpre a função de posicionar de lados antagônicos aqueles que deveriam ser parte de um mesmo grupo, ou seja, o grupo que forma o povo brasileiro.

$\mathrm{O}$ ato discursivo se agrava pelo fato de o comentarista posicionar-se como combatente do racismo e do preconceito, atitude que pode ser desmascarada por meio da análise crítica do discurso tendo como pano de fundo bases reflexivas filosóficas.

Em termos metodológicos, enquadra-se em um trabalho etnográfico em que as falas dos participantes serão materializadas por intermédio dos seus discursos, ou seja, o gêneros que coletamos dentro das mídias comunicativas, especificamente a notícia divulgada no jornal on-line Diário de Pernambuco e o vídeo ao qual tivemos acesso acerca do discurso do comentador/ historiador. A transcrição do discurso constituiu o corpus linguístico para o estudo, a técnica de análise e interpretação desenvolveu-se por meio da interpretabilidade, isto é, o princípio de que o texto se discursiviza na medida em que o pesquisador busca as intenções não explicitadas em sua produção.

\section{Categorização dos discursos}

De acordo com os pressupostos teóricos apresentados e discutidos ao longo desse artigo, os discursos cumprem o papel de reprodução e de manutenção do status quo de manutenção do poder e da hegemonia dentro da nossa sociedade. Desse modo, como forma analítica dos discursos numa perspectiva crítico-filosófica, apresentamos a seguir a categorização de excertos que reafirmam posições preconceituosas e racistas do interlocutor em questão. Trata-se de um texto divulgado pela mídia radiofônica e reproduzido pelo jornal on-line, "Diário de Pernambuco"4 do dia 24 de novembro de 2017 que diz: "Historiador da Jovem Pan adere à onda de ataques a Taís Araújo - 'Haja picaretagem'”. Logo em seguida há o link para ouvir na

4 Disponível no site: http://www.diariodepernambuco.com.br/app/ noticia/viver/2017/11/24/internas_viver,732091/historiador-da-jovem-pan -adere-a-onda-de-ataques-a-tais-araujo-haja.shtm 
íntegra o texto elaborado pelo locutor Marco Antonio Villa ${ }^{5}$, intitulado "Combater o racismo sem falácias".

No corpus linguístico produzido pelo autor e então transcrito nesse artigo, destacamos excertos em que os discursos são usados como instrumento de manutenção de ideologias propagadas ao longo do processo histórico, em que o pensamento filosófico não foi capaz de desconstruir, a exemplo:

A percepção de uma educação eurocêntrica que rebaixa nacionalmente os negros:

[O feriado, por exemplo, de 20 de novembro é uma enorme bobagem. Por que é uma enorme bobagem? Quilombo dos Palmares, centro da liberdade, foco da liberdade "coisa alguma". No Quilombo dos Palmares tinha escravos, "tinha escravos no Quilombo dos Palmares". Não poderia permanecer - como durou tanto tempo - sem estabelecer relações com as outras fazendas, onde havia escravos ali da região, em estabelecer relações comerciais e tal, portanto: "o Quilombo dos Palmares nunca foi um elemento que levou à desagregação da ordem escravista", ao contrário, era um elemento conservador da ordem escravista].

O apresentador apresenta uma postura preconceituosa do interlocutor que se refere à consciência política, ética, estética e ao reconhecimento de características de diversidade étnica:

[você não discute seriamente a escravidão e racismo construindo falácias, como a questão do Zumbi, ou como afirmações que eu vi recentemente de que uma atriz aí dizendo assim "quando eu caminho com meu filho alguém vem e atravessa a rua, vai para a outra calçada". Ah, o que é isso?! E uma atriz da classe dominante que ganha milhões!!! Haja picaretagem! Então, nessa questão que é uma questão séria, insisto, que nós temos de com-

\footnotetext{
5 Biodata: Marco Antonio Villa (São José do Rio Preto, 25 de maio de 1955) é um historiador brasileiro, mestre em Sociologia pela Universidade de São Paulo (1989) e doutor em História Social pela mesma (1993). Professor aposentado da Universidade Federal de São Carlos, atualmente publica comentários e análise sem seu blog, chamado "Blog do Villa". Faz parte da bancada do Jornal da Manhã, na Rádio Jovem Pan. Participa semanalmente da segunda edição do Jornal da Cultura. Fonte: https://pt.wikipedia.org/wiki/ Marco_Antonio_Villa. Acessado em 30 de mar. 2018.
} 
bater, racismo é crime, não é só por ser crime na lei, não importa, tem que ser combatido, nós temos nosso problema da herança escravista que tem que ser combatido rotineiramente, temos de analisar a escravidão, mostrar o horror do seu significado histórico aqui no Brasil, agora, falácia não!, Zumbi herói! Quilombo o centro da liberdade, o foco da liberdade!, essas são falácias construídas e repetidas "ad nauseam" e que não se coaduna com as fontes históricas]

O autor-locutor apresenta valores preconcebidos, de acordo com Nietzsche (1992b) em a Genealogia da moral, conta a história da construção de uma moral que é a expressão de um modo valorativo de dominação e opressão, em que todos os sistemas morais, em última análise, derivam dessas características:

[ter-se uma visão de Brasil que assemelha-se ou ao Sul dos Estados Unidos, e nunca foi aqui, ou pior, África do Sul com essa senhora que diz que pessoas mudam de calçada quando vê-la passar, ela que ganha milhões de reais por ano e é da classe dominante. Portanto, vamos combater o racismo, sim!, todo santo dia sim!, mas sem falácia e sem oportunismo!]

Ao que parece o autor/locutor desconhece outras culturas, uma vez que, parece partilhar o conceito, de acordo com DUSSEL (1992) de que a Europa tornou-se o centro do sistema-mundo devido ao descobrimento, colonização, conquista e subsunção da Ameríndia, conferindo à Europa um benefício importante sobre o mundo otomano-muçulmano, a China ou a Índia. Detentora da administração do centro do sistema-mundo, acredita-se que "nada tem que aprender de outros mundos, outras culturas. Tem um princípio em si mesma e é sua plena realização" (Dussel, 1992, p. 26):

[Zumbi?!, mas quem é Zumbi, teve um monte de Zumbi. Data da morte?! Quem sabe a hora que ele morreu, ninguém sabe o dia, a hora, o momento, as condições, não tem informações fidedignas, documentos para tal, ou trabalhos arqueológicos que pudessem explicar como era Palmares, aí alguns falam: "Palmares era uma república”. República?! O conceito de república inexistia na África nesse tipo de organização, eles tinham uma reprodução africana como se fosse uma organização monárquica. Alguns fa- 
lam "socialistas", socialistas?! Isso é loucura, chamar aquilo de socialista, que socialismo coisa alguma, tinha escravidão, e por que todos estão dizendo isso, porque transformaram a data que "inventaram" da morte do Zumbi num feriado nacional]

O autor-locutor faz uso do discurso para persuadir e convencer os interlocutores, de acordo com Koch (2008), as ações sociais são realizadas por intermédio do discurso, ou seja, ações verbais dotadas de intencionalidade que têm por objetivo tentar influenciar no comportamento do outro ou ainda fazer com que o seu interlocutor compartilhe com ele suas opiniões, valores, formas de pensar e de construir conhecimentos:

[Ah, o que é isso?! E uma atriz da classe dominante que ganha milhões!!! Haja picaretagem! Então, nessa questão que é uma questão séria, insisto, que nós temos de combater, racismo é crime, não é só por ser crime na lei, não importa, tem que ser combatido, nós temos nosso problema da herança escravista que tem que ser combatido rotineiramente, temos de analisar a escravidão, mostrar o horror do seu significado histórico aqui no Brasil, agora, falácia não!]

O autor-locutor faz uso de estratégias de convencimento por meios de recursos de convencimento e de persuasão, pois, de acordo com (Koch, 2008, p. 18) o ato de convencer se dirige unicamente à razão, através de um raciocínio estritamente lógico e por meio de provas objetivas, sendo, assim, capaz de atingir um "auditório universal", possuindo caráter puramente demonstrativo e atemporal. $\mathrm{O}$ ato de persuadir, por sua vez, procura atingir a vontade, o sentimento do interlocutor por meio de argumentos plausíveis ou verossímeis e tem caráter ideológico, subjetivo, temporal, dirigindo-se, pois, a um "auditório particular" (Koch, 2008, p. 18):

[É inquestionável, não é só porque está na lei e na constituição do Brasil, o racismo é crime e temos de combatê-lo todo santo dia, principalmente num país que teve uma escravidão tão longa, foi a última do mundo ocidental a ser abolida, como nós sabemos, a de 13 de maio de 1888, mas desse assunto tem muito oportunista, "muito oportunista"] 
O autor/locutor realiza a utilização dos discursos como forma de controle social, de acordo com Van Dijk (2008), como exemplo de análise e compreensão do discurso, contrapondo-se os discursos e a reprodução do poder social que estes representam, definindo o poder social em termos de controle, isto é, de controle de um grupo sobre outros grupos e seus membros:

[O feriado, por exemplo, de 20 de novembro é uma enorme bobagem. Por que é uma enorme bobagem? Quilombo dos Palmares, centro da liberdade, foco da liberdade "coisa alguma". No Quilombo dos Palmares tinha escravos, "tinha escravos no Quilombo dos Palmares". Não poderia permanecer - como durou tanto tempo - sem estabelecer relações com as outras fazendas, onde havia escravos ali da região, em estabelecer relações comerciais e tal].

É bastante evidente a utilização do éthos do autor com o objetivo de persuadir e convencer, considerando-se o próprio o enunciador, ao construir o seu discurso edifica uma imagem de si, a essa imagem denominamos éthos do enunciador. Cabe destacar que é o éthos que leva à persuasão, de acordo com Aristóteles, apud Fiorin (2017) é o éthos que leva à persuasão quando organizado de tal forma que o orador inspira confiança, isto é, confiamos sem dificuldade em homens ditos de bem, assim, o comentador da Rádio Jovem Pan usa o próprio éthos para influenciar os interlocutores:

[ter-se uma visão de Brasil que assemelha-se ou ao Sul dos Estados Unidos, e nunca foi aqui, ou pior, África do Sul com essa senhora que diz que pessoas mudam de calçada quando vê-la passar, ela que ganha milhões de reais por ano e é da classe dominante. Portanto, vamos combater o racismo, sim!, todo santo dia sim!, mas sem falácia e sem oportunismo!]

Assim, pelos excertos apresentados, vimos mais uma vez se consolidar nos meios de comunicação, a dizer, a comunicação radiofônica, a manutenção do racismo, de preconceitos e de atos discriminatórios por meio do uso dos discursos ideológicos que reafirmam que a sociedade brasileira deve tornar opaca ou mesmo invisível quanto às disparidades presentes nas relações étnico-raciais em que os negros, quando não são tratados como inferiores, são negligenciados, como se não pudes- 
sem ocupar qualquer lugar de destaque social, baseados em uma ética etnocêntrica que opacifica as diversidades culturais.

\section{Apontamentos (in- conclusivos) para o combate ao pre- conceito e ao racismo numa perspectiva educacional}

As discussões de novas estratégias de enfrentamento do racismo, apesar de necessárias, em alguns casos, pautamse em discursos banalizados e comprometidos por conteúdos vazios, demonstrando que discursos de pessoas com notoriedade pública podem repercutir e persuadir seus interlocutores, estabelecendo certo domínio, conforme se observa na entrevista do historiador Villa, intitulada "Combater o racismo sem falácias: o Quilombo dos Palmares nunca foi um elemento que levou à desagregação da ordem escravista, ao contrário, era um elemento conservador da ordem escravista" (Villa, 2017). Este discurso, por exemplo, não leva em consideração a postura de resistência dos negros frente às inúmeras condições adversas enfrentadas, ao contrário, difunde em seu cerne concepções ideológicas, acríticas que se contrapõem a perspectiva de superação das discriminações, pois acaba reforçando mensagens preconceituosas no que tange às classificações referentes à etnia das pessoas, em todos os ambientes sociais, não deixando de ocorrer também nos ambientes educacionais.

Conforme a interpretação nietzschiana, aqueles que vivem somente para obedecer, suprimem os instintos e pulsões concernentes em si mesmos, agem segundo uma única verdade e moral, que dita o certo e o errado. Para a expressão de um novo percurso de vida é necessário enfrentar as forças externas que pressionam à uma conduta de obediência. Para combater as tentativas de nivelamento humano é preciso ser forte e audaz, pois somente assim se observa a importância da não existência de uma única verdade ou forma a seguir.

Nesse sentido, ao que se refere às práticas educacionais, uma maior atenção e cuidado dos educadores são requeridos no trato de assuntos relacionado às questões raciais, haja vista o acesso facilitado aos conteúdos com formas implícitas e cristali- 
zadoras de um posicionamento dominante, posto que esses discursos perduram ao longo das épocas e as escolas, todavia, ainda reproduzem relações de poder e precisam buscar mecanismos específicos para atuar na mitigação das ações discriminatórias.

Conforme Coelho e Silva (2013), uma parcela considerável da responsabilidade pela disseminação de preconceitos e de posturas mantenedoras de ações discriminatórias no ambiente escolar deve-se a uma formação docente deficiente, dado que a maioria dos cursos de formação não instrui de maneira adequada os profissionais para confrontar o sistema educacional em sua amplitude propagando dispositivos discriminatórios e preconceituosos. De acordo com as autoras, vários profissionais pressupõem que a discussão dessas temáticas resulta eventualmente na incitação do racismo no ambiente escolar, uma equivocada compreensão de que a escola encontra-se imune aos embates étnico-raciais observados na sociedade brasileira.

No século da informação, da ciência, do conhecimento e da tecnologia e de diversos progressos da era digital, atitudes racistas, sobretudo, nas escolas e locais públicos são propagadas incisivamente. Por isso, utilizar a entrevista de Villa (op. Cit.), enquanto recurso didático capaz de promover um debate crítico sobre como esse meio de comunicação pode, a depender do ponto de vista do interlocutor, em vez de disseminar um comportamento de combate ao preconceito e ao racismo, acabar por representar um recurso incentivador, por exemplo, da segregação racial.

Segundo Munanga (2005), a escola como parte integrante da sociedade, deve, através da aprendizagem, comprometer-se com a transformação de perspectiva organizada, planejada e consciente, subsidiando os docentes e os alunos na assimilação de que as diferenças são benéficas e engrandecedoras. Esse entendimento pode suscitar o respeito às diferenças, às características únicas de cada um.

Com isso, ao procurar e gerar as resoluções dirigimonos para o reconhecimento e proteção dos direitos humanos e do exercício da cidadania. De tal modo, que a educação passe a ser compreendida como paideia, ou seja, termo grego que ex- 
pressa "educação cultural", normalmente compreendido como uma educação integral do ser humano, concernente a uma formação que assegure aquisição de conhecimento científico e filosófico, mas, sobretudo, forme o indivíduo para uma conduta cidadã, capaz de respeitar, honrar e ser virtuoso em suas práticas na comunidade.

Assim segundo, Jaeger (2003, p. 3) "assegura que toda sociedade que alcança algum estágio de progresso inclina-se à realização da educação, o espírito humano conduz progressivamente à descoberta de si próprio e cria, pelo conhecimento do mundo exterior e interior, formas melhores de existência humana". A educação precisa exercer sua função de promotora de conhecimento, criadora de cidadãos reflexivos e críticos e com diferenciada mentalidade frente às estruturas de poder e as relações constituídas entre os indivíduos, para que discursos como esse apresentado não façam efeito ideológico para a formação e constituição social dos cidadãos.

\section{Referências}

ASANT, MolefiKete. Uma origem africana da filosofia: mito ou realidade?. Capoeira - Revista de Humanidades e Letras $\mid$ Vol.1 | No. 1 | Ano 2014. Disponível em: http://www.capoeirahumanidadeseletras. com.br/ojs2.4.5/index.php/capoeira/article/view/13/12. Acesso em: 30 de junho de 2018.

BAKHTIN, MIKHAIL (VOLOSHÍNOV). Marxismo e filosofía da linguagem. São Paulo: Hicitec, 2009.

BARRENECHEA, M. Angel. Nietzsche: memória trágica e futuro revolucionário. In: FEITOSA, Charles. (Orgs.) A fidelidade à terra. Rio de Janeiro: DP\&, 2003.

BERNSTEIN, Basil. Class, code and control 4: the structuring of pedagogic discourse. London and New York: Routledge, 1990.

BRASIL. Lei $n^{\circ} 10.639$, de 09 de janeiro de 2003. Altera a Lei $n^{\circ}$ 9.394, de 20 de dezembro de 1996, que estabelece as diretrizes e bases da educação nacional, para incluir no currículo oficial da Rede de Ensino a obrigatoriedade da temática "História e Cultura Afro -Brasileira", e dá outras providências. Brasília, 2003. Disponível em: < http://www.planalto.gov.br/ccivil_03/leis/2003.htm>. Acesso em 02 de mar. 2018.

BRASIL. Lei $n^{\circ} 11.645$, de 10 de março de 2008. Altera a Lei $n^{\circ}$ 9.394, de 20 de dezembro de 1996, modificada pela Lei $n^{\circ} 10.639$, 
de 09 de janeiro de 2003, que estabelece as diretrizes e bases da educação nacional, para incluir no currículo oficial da Rede de Ensino a obrigatoriedade da temática "História e Cultura Afro-Brasileira e Indígena". Disponível em: < http://www.planalto.gov.br/ ccivil 03/ ato2007-2010/2008/lei/111645.htm >. Acesso em 03 de mar. $\overline{2} 018$.

BRASIL. Lei $n^{\circ}$ 9.394, de 20 de dezembro de 1996. Estabelece as diretrizes e bases da educação nacional. Diário Oficial da União. Brasília, 23 dez. 1996. Disponível em: < http://www.planalto.gov. br/ccivil_03/leis/9394.htm>. Acesso em 01 de mar. 2018.

CHARTIER, Roger. $O$ mundo como representação. Revista Estudos Avançados, São Paulo, v. 11, n. 5, 1991, p. 173-191.

CLORAN, Carmel. Socio-Semantic Variation: Different Wordings, Different Meanings. In: Unsworth, L. (Org.) Researching Language in Schools and Communities. London: Cassel. 2000, p. 152-183.

COELHO, Wilma de N. B. A questão racial na escola: um estudo sobre as representações dos agentes da escola sobre os conteúdos étnico culturais. Belém: UNAMA, 2010.

COELHO, Wilma de N. B. Educação história e problemas: cor e preconceito em discussão. Belo Horizonte: Mazza Edições, 2012.

COELHO, Wilma de N. B.; SILVA, Rosângela M. de N. B. Relações raciais e educação: o estado da arte. Revista Teias, V. 14, n. 31. maio/ ago, 2013. Pp. 121-146.

DUSSEL, Enrique. 1492: el encubrimiento del otro: hacia el origen del mito de la modernidad. Madrid: Nueva Utopia, 1992. Conferências de Frankfurt.

DUSSEL, Enrique. Filosofia da Libertação: crítica à ideologia da exclusão. Trad. de George I. Maissiat. São Paulo: Paulus, 1995.

DUSSEL, Enrique. Ética da Libertação na idade da globalização e da exclusão. Petrópolis: Vozes, 2000.

DUSSEL, Enrique. Seminário de ética. México: Unam, 2001b.

DUSSEL, Enrique. Seminário de ética. México: Unam, 2001c.

FAIRCLOUGH, Norman. Language and power. London: Longman, 1989.

FERNANDES, Florestan. Pronunciamentos. Brasília: Câmara dos Deputados, Centro de Documentação e Informação, 1993.

FIORIN, José Luiz. Argumentação. São Paulo: Contexto, 2017.

FOUCAULT, MICHEL. O sujeito e o poder. In: RABINOW, p. ; DREYFUSS, H. Michel Foucault: uma trajetória filosófica. Rio de Janeiro: Forense Universitária, 1995. 
HALLIDAY, Michael.A, K. e HASAN, Ruqaiaya. Language, Context and Text: aspects of language in a social semiotic perspective. Oxford. Oxford University Press. 1989.

JAEGER, Werner. Paideia: A formação do homem grego. Tradução de Artur M. Parreira. São Paulo: Martins Fontes, 2003.

KOCH, Ingedore G. Villaça. Argumentação e linguagem. São Paulo: Cortez, 2008.

MACHADO, Roberto. Nietzsche e a verdade. Rio de Janeiro: Rocco, 1999.

MILLER, Carolyn R. Gênero textual, agência e tecnologia. São Paulo: Parábola, 2012.

MUNANGA, Kabengele. (Org.). Superando o racismo na escola. 2. ed. Brasília: Ministério da Educação, Secretaria de Educação Continuada, Alfabetização e Diversidade, 2005.

NIETZSCHE, Friedrich W. A genealogia da moral. Petrópolis. Trad. Mario Ferreira dos Santos. Rio de Janeiro: Vozes, 2009a.

NIETZSCHE, Friedrich.W. Além do bem e do mal: prelúdio a uma filosofia do futuro. Trad. Paulo Cezar de Souza.São Paulo: Companhia das Letras, 1992a.

NIETZSCHE, FriedrichW. O nascimento da tragédia ou helenismo e pessimismo. Trad. J. Guinsburg. São Paulo: Companhia das Letras, 1992b.

NOGUEIRA, Renato. Contra o (maior) tabu da Filosofia: ensino de Filosofia e os 10 anos da Lei ${ }^{\circ} 10.639 / 03$. In: COELHO, W. N. B... [et al.] (org.) A Lei 10.639/2003: pesquisas e debates. São Paulo: Editora Livraria da Física, 2014.

POSSENTI, Sírio. Notas sobre língua, texto e discurso. In: BRAIT, Beth, e SOUZA-E.SILVA, Maria Cecília. Texto ou Discurso. São Paulo: Contexto, 2012.

VAN DIJK, Teun. A. Discurso e Poder. São Paulo: Contexto, 2008.

VERNANT, Jean-Pierre. Mito e Pensamento entre os gregos. Trad. de Haiganuch Sarian. Rio de Janeiro: Paz e Terra, 1990. 